\title{
A comunicação eletrônica e a alteração de tempo e espaço na produção do conhecimento científico $[1]^{*}$
}

Rubenildo Costa

Mestre em ciência da informação/PUC-Campinas.

E-mail: rubinhocosta2002@yahoo.com.br

\begin{abstract}
Resumo
Versa sobre a influência da comunicação eletrônica na produção do conhecimento científico na área de física da Universidade Estadual de Campinas entre o início das décadas de 1980, 1990 e 2000. Verifica se o acesso mais abrangente e rápido à informação científica proporcionado pelos periódicos eletrônicos e seus estoques ou portais tem ocasionado modificações no sujeito cognoscente. Por meio da correlação entre dados de dissertações/teses e dados retirados de suas referências bibliográficas (títulos de periódicos citados e anos de publicação), conclui-se que os pesquisadores estão citando mais títulos de periódicos e mais rapidamente, talvez por conta do fenômeno da comunicação eletrônica.
\end{abstract}

\section{Palavras-chave}

Periódicos eletrônicos. Comunicação eletrônica. Produção científica. Cognição. Bibliometria. Dissertações e teses.

The electronic communication and the alteration of time and space in the productic of the scientific knowledge

\section{Abstract \\ It verbalizes the influence of electronic communication over scientific knowledge production in the Physics space of the State University of Campinas between the begin of the decades of 1980, 1990 and 2000. It is verified if the most including and fast access to the scientific information, proportionate for the Electronic Journals and its Collections or Search Engines, has caused to modifications in the cognoscente citizen. Through of the correlation between data of dissertations/thesis and removed data of its bibliographical references (articles of journal cited and years of publication), it is concluded that the researchers are citing more articles of journal and more quickly, perhaps for account of the phenomenon of the electronic communication.}

\section{Keywords}

Electronic journals. Electronic communication. Scientific production. Cognition. Bibliometrics. Dissertations and thesis.

* As notas de rodapé encontram-se ao final do artigo.

\section{INTRODUÇÃO}

A comunicação eletrônica alterou o acesso a estoques de periódicos científicos. Os estoques de periódicos eletrônicos (EPEs), ou portais, permitem novo modo de acesso, em que os usuários não só podem utilizar o mesmo material ao mesmo tempo (interoperabilidade), como também utilizá-lo velozmente, sem o incômodo do deslocamento físico à biblioteca. Logo, a dimensão tempo tende a zero. Contam, ainda, com novo modo de arquivamento, proporcionando acervos mais abrangentes, em que inexiste a preocupação com o espaço, possibilitando maior oferta de periódicos aos usuários. Logo, a dimensão espaço é transparente.

Tais alterações nos estoques entram em consonância com a afirmação de que houve uma modificação estrutural (tempo e espaço) no fluxo de informação científica provocada pela comunicação eletrônica (BARRETO, 1998).

Assim, o Portal de Periódicos Eletrônicos da Coordenadoria de Aperfeiçoamento de Pessoal do Ensino Superior (Portal/Capes), por exemplo, caracteriza-se como um EPE. Surgido em 2000 e considerado o maior da América Latina, disponibiliza atualmente cerca de 11.400 títulos de periódicos eletrônicos internacionais, nacionais e estrangeiros com acesso ao texto integral a 163 instituições participantes [2]. Portanto, traz características marcantes como novo modo de acesso e arquivamento.

Nesse contexto, a questão principal é saber se essa alteração de tempo e espaço nos estoques provocou, de igual modo, alterações na produção do conhecimento científico na área de física da Universidade Estadual de Campinas (Unicamp); em outras palavras, como a produção do conhecimento científico e pesquisadores, entendidos aqui como sujeitos cognoscente, têm sido afetados pela dinamização do acesso em rede.

$\mathrm{O}$ interesse em investigar os impactos das tecnologias no sujeito cognoscente é característico da corrente cognitivista presente na ciência da informação (CI). Tal corrente surgiu na década de 1980 com a teoria do Estado Anômalo do Conhecimento (Anomalous State of 
Knowledge - ASK), conjecturada por Nicholas Belkin [3] e outros. Atualmente, após sofrer críticas por possuir um enfoque idealista e individualista que considera somente o sujeito cognoscente (CAPURRO, 2003), a corrente cognitivista tem se correlacionado com as características social e fisicista do objeto informação.

Barreto (2007) tem investigado sobre a apropriação da informação em hipertextos. Supõe que a assimilação da informação nesse suporte é mais abrangente e mais individualista, já que tal estrutura permite uma leitura não-linear e não seqüencial. "As estruturas, entrelaçadas e distribuídas em rede, certamente, reposicionarão as condições de apropriação da informação" (grifos nossos).

Seguramente, a distribuição de periódicos na rede causou uma mudança estrutural (tempo e espaço) em estoques de periódicos. Entretanto, o fluxo envolve não só estoques, mas também os pesquisadores e sua produção, sobre os quais se pretende investigar.

Para isso, parte-se da proposição de que a análise dos títulos de periódicos citados e seus respectivos anos nas dissertações/teses de determinado domínio - desde a introdução dos primeiros periódicos eletrônicos (início da década de 1980), passando pelas redes (por volta década de 1990) até a implementação desses recursos em sistemas de informação ou portais (década de 2000) pode fornecer elementos favoráveis à compreensão do fenômeno proposto.

\section{PROCEDIMENTOS METODOLÓGICOS}

O universo é formado pelas dissertações/teses defendidas no início de três décadas (1980, 1990 e 2000) no Instituto de Física Gleb Wataghin da Unicamp - uma das participantes do Portal/Capes. A quantidade de trabalhos analisados foi de 15 em 1983, 29 em 1984, 42 em 1985, 33 em 1993, 52 em 1994, 44 em 1995, 51 em 2003, 41 em 2004 e 30 em 2005, os quais totalizam 337 registros.

A escolha dos anos a serem pesquisados se justifica pelo fato de ter sido em meados da década de 1980 a época em que se criaram os primeiros periódicos eletrônicos (STUMPF, 1996; ROWLEY, 2000; BIOJONE, 2003), de ter sido em torno da década de 1990 a sua disponibilização na rede (MARCONDES; GOMES, 1997; BIOJONE, 2003; CEDÓN, 2003) e de ter sido por volta da década de 2000 a sua concentração em sistemas de informação para melhor disseminá-los, por exemplo, os consórcios e portais (KRZYZANOWSKI; TARUHN, 1998; PAULA NETO, 2005; AMORIM; VERGUEIRO, 2006).
A justificativa da escolha das dissertações/teses é, primeiramente, pelo fato de os pós-graduandos serem um dos grupos que mais utilizam os periódicos científicos no desenvolvimento de trabalhos de pesquisa nas universidades, uma vez que, segundo King e Tenopir (1998, p. 176), 75\% das leituras de periódicos científicos visam à pesquisa, e também pelo fato de esses trabalhos serem fontes confiáveis com alto grau de institucionalização e avaliação por pares (PARLEMITI; POLITY, 2002; KOBASHI; SANTOS, 2006), que atestam de fato, por meio das citações, o uso de periódicos.

O campo da física se justifica pelo fato de ser uma das áreas que mais utilizam periódicos, conforme estatísticas de acesso da Unicamp, bem como por ser a única na Universidade, até o momento, a disponibilizar na rede sua coleção completa de dissertações/teses, aspecto que facilita a coleta e manipulação dos dados.

A coleta dos dados foi realizada por meio da recuperação dos títulos de periódicos citados e seus respectivos anos de publicação junto às referências bibliográficas das dissertações/teses, disponíveis eletronicamente no site do Instituto de Física, e também de seus dados bibliográficos (autor, título, ano de defesa, descritores, tipo de documento [dissertação ou tese] e orientador) junto ao catálogo bibliográfico em linha da universidade - o "Virtua".

Em resumo, o objeto de estudo compreende a correlação entre dados bibliográficos das dissertações/teses e dados retirados de suas referências bibliográficas (títulos de periódicos citados e anos de publicação).

Cabe aqui elucidar que essa correlação entre propriedades bibliográficas é a essência da bibliometria. Estudos dessa natureza têm apresentado certas regularidades quando classificadas as propriedades em uma ordem de freqüência, produzindo uma espécie de distribuição. As distribuições de Lotka, Bradford e Zipf têm, sempre, o mesmo aspecto gráfico - núcleo e dispersão. Por isso, são consideradas como modelos e/ou leis bibliométricos. $\mathrm{O}$ núcleo expressa identidade e/ou redundância, enquanto a dispersão expressa individualidade e/ou variedade do conhecimento científico. No caso de Lotka, por exemplo, cruzou-se a propriedade autor com a propriedade assunto e estabeleceu-se que 20\% dos autores publicam $80 \%$ sobre determinado assunto, enquanto que $80 \%$ publicam 20\%. Do mesmo modo são os estudos de Bradford e Zipf.

Antes da apresentação da próxima seção, cabem alguns esclarecimentos sobre os termos ou formas de contagem adotados em distribuições bibliométricas (Lotka, Bradford e Zipf), a fim de que se tenha melhor compreensão das figuras apresentadas a seguir. 
O primeiro é o termo freqüência, que representa a contagem do dado, sem computar repetições no campo em estudo, em cada registro de dissertação/tese. A ocorrência, porém, representa a contagem do dado, computando suas repetições no campo em estudo de cada registro de dissertação/tese.

Essas contagens permitem a obtenção de freqüência e ocorrência absolutas, relativas e relativas acumuladas dos elementos bibliográficos estudados. As medidas relativas e relativas acumuladas, tomadas em porcentagem, são imprescindíveis para o estabelecimento e representação das distribuições bibliométricas. Permite-se, então, comprovar o comportamento de núcleo e dispersão, como já destacado anteriormente.

\section{APRESENTAÇÃO E ANÁLISE DOS RESULTADOS}

Esta seção se subdivide em duas nas quais são abordados os dois temas centrais deste estudo, representados pela verificação do núcleo de títulos de periódicos citados e dos seus respectivos anos de publicação, nas três décadas consideradas: 1980, 1990 e 2000.

Assim, a determinação da ocorrência relativa acumulada neste estudo permitiu identificar o núcleo geral dos títulos de periódicos citados nas três décadas, determinado a partir da ocorrência total de citações dos periódicos citados (16.380) e ocorrência total de títulos de periódicos citados (1.719).

O núcleo geral é formado por apenas 22 títulos de periódicos e representa 50\% (8.224) do total de ocorrência de citações (16.380). Não se consideraram,

\section{FIGURA 1}

Comportamento das ocorrências e freqüências relativas das citações do núcleo geral nas três décadas

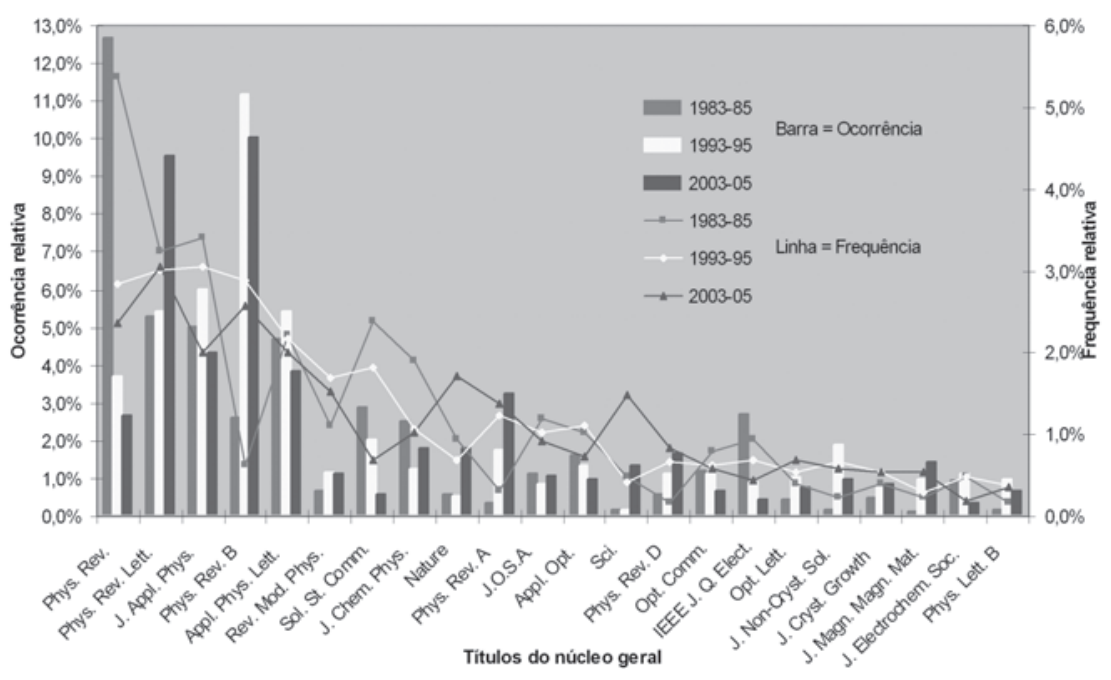

nesse caso, os $80 \%$ do total da ocorrência das citações, conforme recomendam os modelos bibliométricos, porque o número total de 144 títulos de periódicos já incluía excessiva quantidade de dispersão de títulos de periódicos, e isso, provavelmente, inviabilizaria as análises e a formulação de representações do fenômeno. Dessa forma, estabeleceram-se, para composição do núcleo geral, 22 títulos de periódicos, sobre o qual se desenvolve a próxima seção [4].

\section{O comportamento do núcleo de periódicos nas três décadas $(1980,1990$ e 2000)}

Nas próximas duas figuras, estuda-se o comportamento dos 22 títulos nas três décadas, a fim de analisar as possíveis variações no número de citações, possivelmente causadas pelo fenômeno da comunicação eletrônica.

Porém, não se pode afirmar, desde já, que tal fenômeno seja a principal causa interferente na citação, como bem colocam Harnad e Brody (2004): "Access is not a sufficient condition for citation, but it is a necessary one" [5]. Entende-se que não é somente a simples disponibilização na rede que poderá aumentar o uso de um periódico, mas sim o seu valor perante a comunidade científica. Além disso, existe o aspecto do crescimento exponencial no número de títulos em todas as disciplinas, conforme estudos realizados por Solla Price (1976), indicando que esse número dobrava a cada 15 anos.

Assim, a figura 1 é uma representação gráfica, em dois eixos, das ocorrências e das freqüências relativas, permitindo visualizar o comportamento relativo das citações nas três décadas estudadas.

A figura 1 mostra a importância de determinado título em relação ao número total de ocorrência. Por exemplo, o título Phys. Rev. tem a maior ocorrência relativa acima de $12 \%$ em relação ao número total de ocorrência de 3.148 na década de 1980. O título Phys. Rev. B tem a ocorrência relativa acima de $11 \%$ em relação ao número total de ocorrência de 5.908 na década de 1990. Ou seja, as maiores percentagens registradas.

Nesse ponto, percebe-se uma tendência de concentração de citação em um só título. Porém, esse comportamento vem se desfazendo da década de 1980 a de 2000 . Ou seja, 
verifica-se que, enquanto um único título da década de 1980 alcança mais de $12 \%$, outros têm as piores percentagens. Já os títulos da década de 2000 são mais homogêneos nas citações, ou seja, há menos discrepâncias, ou melhor, há certa homogeneização nas citações das teses/dissertações da década de 2000 em relação a da década de 1980.

Por exemplo, na década de 2000 a concentração se dá em dois títulos (Phys. Rev. Lett. e Phys. Rev. B), enquanto a concentração nas duas primeiras décadas se dá em apenas um título (Phys. Rev. e Phys. Rev. B).

Embora o título Phys. Rev. na década de 1980 possa parecer superior, ele tem apenas 399 ocorrências. Aliás, essa ocorrência é maior na década de 1980, decaindo para a casa das 100. Já na década de 1990, houve registro de 661 ocorrências do título Phys. Rev. B, decaindo para a casa das 300 .

A figura 2 é uma representação gráfica em dois eixos das ocorrências e freqüências das citações tomadas em valor absoluto, o que permite mostrar o comportamento real dos títulos nas décadas estudadas.

Se forem comparadas as duas últimas figuras, é possível verificar que, no caso da barra do título. Phys. Rev. da década de 1980 decaiu consideravelmente nesta última figura. Isso porque esse título, ao passo que teve 399 ocorrências simples, teve importância naquela década maior do que qualquer outro título nas duas últimas décadas. Isto é, ele teve uma ocorrência relativa de $12,67 \%$. Outro título que teve importância um pouco inferior foi o do Phys. Rev. B na década de 1990 com $11,19 \%$, porém o mesmo título teve a ocorrência simples maior de todas na década de 2000, 736 ocorrências. Ademais, vale lembrar que esse segundo título é uma subdivisão do outro.

As barras de ocorrência da figura sinalizam que a década de 2000 (em azul) influencia mais o núcleo geral, com maior número de citação dos 22 títulos do núcleo geral. Isso é mais perceptível em sete títulos (Phys. Rev. Lett., Phys. Rev. B, Nature, Phys. Rev. A, Sci., Phys. Rev. D, J. Magn. Magn. Mat.). Esses títulos têm uma ocorrência de citações de 702, 736, 134, 238, 99, 124 e 107, respectivamente.

FIGURA 2
Aqui, pode-se afirmar que talvez a dinamização no acesso tenha influenciado no maior número de ocorrências da década de 2000.

Outro ponto importante é a permanência dos primeiros cinco títulos (Phys. Rev., Phys. Rev. Lett., J. Appl. Phys., Phys. Rev. B e Appl. Phys. Lett.) nas três décadas. Ou seja, esses títulos ocupam sempre as cinco primeiras posições nas três décadas. A explicação para o fato de que o Phys. Rev. tenha saído do primeiro lugar nas últimas décadas é porque esse título sofreu uma subdivisão em A, B, C, D e E. Por isso, o Phys. Rev. B ocupou o seu primeiro lugar nas últimas duas décadas, ao passo que o Phys. Rev. decaiu.

Nesse ponto, vale reafirmar que não é somente a simples disponibilização na rede que poderá aumentar o uso de um periódico, mas sim o seu valor perante a comunidade científica. Como visto, os principais periódicos da área se mantiveram no topo nas três décadas estudadas.

Até aqui as constatações tiveram como base o núcleo geral que foi definido considerando a soma das três décadas. A partir disso, realizou-se a ocorrência relativa acumulada para definir os 22 títulos que satisfazem $50 \%$ da ocorrência geral. Assim, acompanhou-se o comportamento desse núcleo geral nas três décadas.

A partir da próxima figura, entretanto, representa-se o comportamento do uso de títulos de periódicos nas três décadas, considerando, diferentemente das últimas figuras, o total de títulos de cada década e seu núcleo

Comportamento das ocorrências e freqüências, em valor absoluto, das citações do núcleo geral nas três décadas

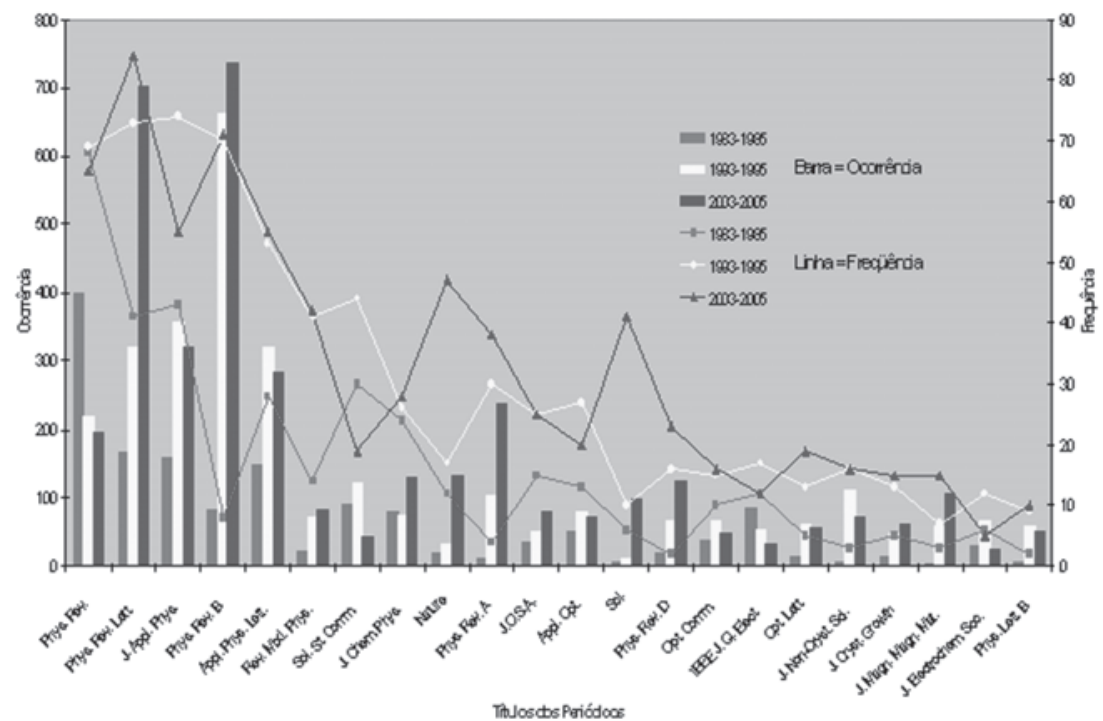


específico, que satisfaz os $80 \%$ das ocorrências ou os mais citados nas suas respectivas décadas. Ademais, coloca-se mais uma variável - a questão do aumento do número de títulos citados.

De acordo com a figura 3 e considerando os modelos bibliométricos de Lotka, Bradford e Zipf, pode-se afirmar que $20 \%$ dos títulos citados representam $80 \%$ das ocorrências, enquanto $20 \%$ das ocorrências representam $80 \%$ dos títulos citados.

\section{FIGURA 3}

Distribuição relativa acumulada dos títulos citados em cada núcleo, segundo $80 \%$ das ocorrências

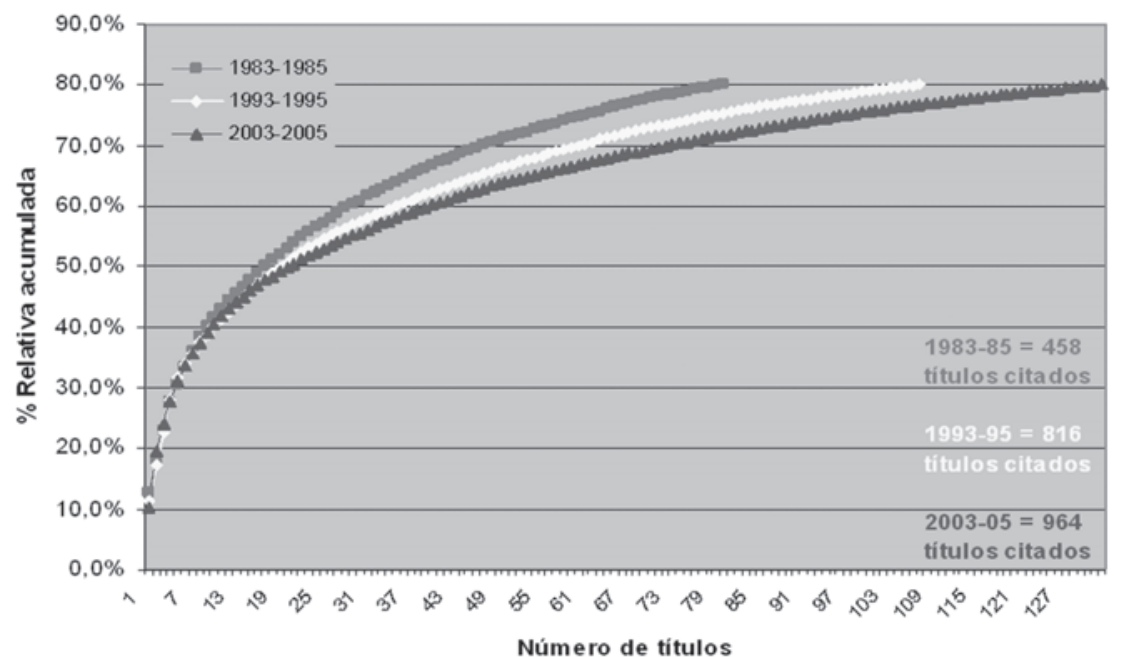

aumento no número de títulos citados que fazem parte de cada núcleo e do total de cada década, como também das ocorrências desses títulos em cada década.

Na década de 1980, o núcleo (ou 80\% mais citados) é formado por 80 títulos, ao passo que nas décadas de 1990 e 2000, por 107 e 132 títulos, respectivamente. Logo, da primeira para a segunda década, o aumento foi de 27 títulos e, da segunda para a terceira década, o aumento foi de 25 títulos. Ou seja, parece ter havido aumento no número de títulos no núcleo de cada década.

Da mesma maneira, na contagem geral de títulos em cada década, observou-se um aumento. $\mathrm{Na}$ década de 1980, o número de títulos citados no geral é de 458, enquanto nas seguintes décadas é de 816 e 964, respectivamente. Logo, da década de 1980 para a de 1990, o aumento de títulos citados é de 358 títulos e, da década de 1990 para o de 2000 , o aumento foi somente de 148 títulos.

Em contrapartida, no que se refere ao aumento de ocorrências em cada década, poder-se-ia supor que a década de 1990 teria o maior número de ocorrências, uma vez que

Logo, na década de 1980, apenas 80 títulos representam $80 \%$ das ocorrências, formando, portanto, o núcleo; os outros 378 títulos restantes representam 20\% das ocorrências, formando a dispersão.

Na década de 1990, 107 títulos representam 80\% das ocorrências, formando, portanto, o núcleo; os outros 709 títulos restantes representam $20 \%$ das ocorrências, formando a dispersão.

Na década de 2000, 132 títulos representam 80\% das ocorrências, formando, portanto, o núcleo; os outros 832 títulos restantes representam 20\% das ocorrências, formando a dispersão.

É preciso considerar também erros na contagem de títulos citados. Por conta dos métodos de transcrição e conversão na coleta de dados e, principalmente, pelas diferentes maneiras de se abreviar cada título, muitos foram contados mais de uma vez - é possível constatar isso observando o grande número de dispersão em cada década.

Contudo, existem importantes observações a serem apresentadas que dizem respeito não só a questão do obtém mais dissertações/teses defendidas (129), precedido pelas décadas de 2000 e 1980 (122 e 86, respectivamente). Ou seja, teve mais chance de citar, por isso sua ocorrência deveria ser alta. Porém, é a década de 2000 que possui o maior número (7.324), precedido pelas décadas de 2000 e 1980 (5.908 e 3.148, respectivamente).

Mais especificamente, a média de citação por unidade de dissertação/tese na década de 2000 também é maior (60), seguida das décadas de 1990 e 1980 (46 e 37, respectivamente). Ou seja, houve, de fato, aumento crescente no número de ocorrência de citação em cada dissertação/tese.

É importante observar também a discrepância no número total de citações entre as três décadas. A diferença entre a década de 1980 e a de 1990 é de 2.760 citações, enquanto, entre a década de 1990 e a de 2000, é de 1.416. Ou seja, a diferença é maior no primeiro caso.

Por fim, parece conveniente afirmar que, seja por conta de coleções mais abrangentes e de fácil acesso proporcionado pela comunicação eletrônica, ou pelo 
aumento exponencial de títulos em todas as disciplinas, os pesquisadores estão citando mais títulos, ou melhor, aumentaram-se o número de títulos citados e a ocorrência de citação de títulos de periódicos em cada dissertação/tese.

\section{O comportamento dos anos de periódicos citados nas três décadas (1980, 1990 e 2000)}

A medida do grau da rapidez da comunicação científica por meio de periódicos eletrônicos se torna importante caso se considere que, antes das redes, um título de periódico estrangeiro impresso delongava por volta de seis meses, datado da sua publicação, para se tornar disponível para os pesquisadores nas prateleiras das bibliotecas. Isso resultava em certo atraso das pesquisas brasileiras em relação às de nações mais desenvolvidas. A questão da alteração do tempo de citação provocada pela comunicação eletrônica se torna aqui mensurável.

Um dos estudos mais comentados sobre esse tema é o de Lawrence (2001) que, em seu estudo empírico no campo da ciência da computação, revelou que os artigos de periódicos citados com datas mais recentes são mais prováveis serem eletrônicos. O número médio de citação artigos impressos é de 2.74, enquanto que o dos eletrônicos é de 7.03, um aumento de 157\%.

Outro estudo similar é o de Shin (2004). Embora utilizando dados enviesados da Thomson ISI (Institute for Information Scientific), verificou a influência da publicação eletrônica na área de educação sobre o Índice de imediaticidade de citação, utilizando-se de margem temporal de nove anos (1995-2003). Esse indicador apresenta quão rapidamente o artigo é citado após a sua publicação. E concluiu que o Índice de imediaticidade aumentou significativamente nesse período.

Outro estudo importante é da própria Thomson ISI (TESTA; McVEIGH, 2004). Examinou a velocidade relativa em que um artigo de acesso livre é citado, comparado com outros que não o são. Utilizaram-se todas as citações do ano 2002, considerando as citações desse ano e de três anos anteriores.

FIGURA 4
Revelou que existe uma tendência em citações mais recentes nos artigos de acesso livre.

A figura 4 representa a freqüência em que determinado ano do periódico é citado nas dissertações/teses, de acordo com as datas de defesas.

De acordo com a figura 4, o número 1 significa quantas dissertações/teses citaram um ou mais periódicos de ano igual ao da suas defesas. Por exemplo, a linha verde de 1983 indica que uma dissertação/tese, das 15 que foram defendidas nesse ano, citou títulos de periódicos do mesmo ano, quatro citaram títulos de um ano anterior da defesa, ou seja, 1982, e 10 citaram títulos de dois anos antes da defesa, ou seja, 1981, e assim por diante.

Convém ressaltar que a freqüência é dependente do número de dissertações/teses defendidas em determinado ano ou década. No caso da década de 1980, somente 86 dissertações/teses foram defendidas. Em vista disso, como forma de adequar o número de freqüência à quantidade de dissertações/teses defendidas em cada década, entende-se que a soma da percentagem seria mais adequada para verificar a realidade em cada década.

Assim, das 86 dissertações/teses defendidas na década de 1980, 17,44\% citaram títulos de periódicos do mesmo ano de defesa; na década de 1990, 43,41\% de 129 citaram títulos de periódicos do mesmo ano de defesa; na década de 2000, 41,80\% de 122 citaram títulos de periódicos do mesmo ano de defesa.

Freqüência do ano de periódicos citados

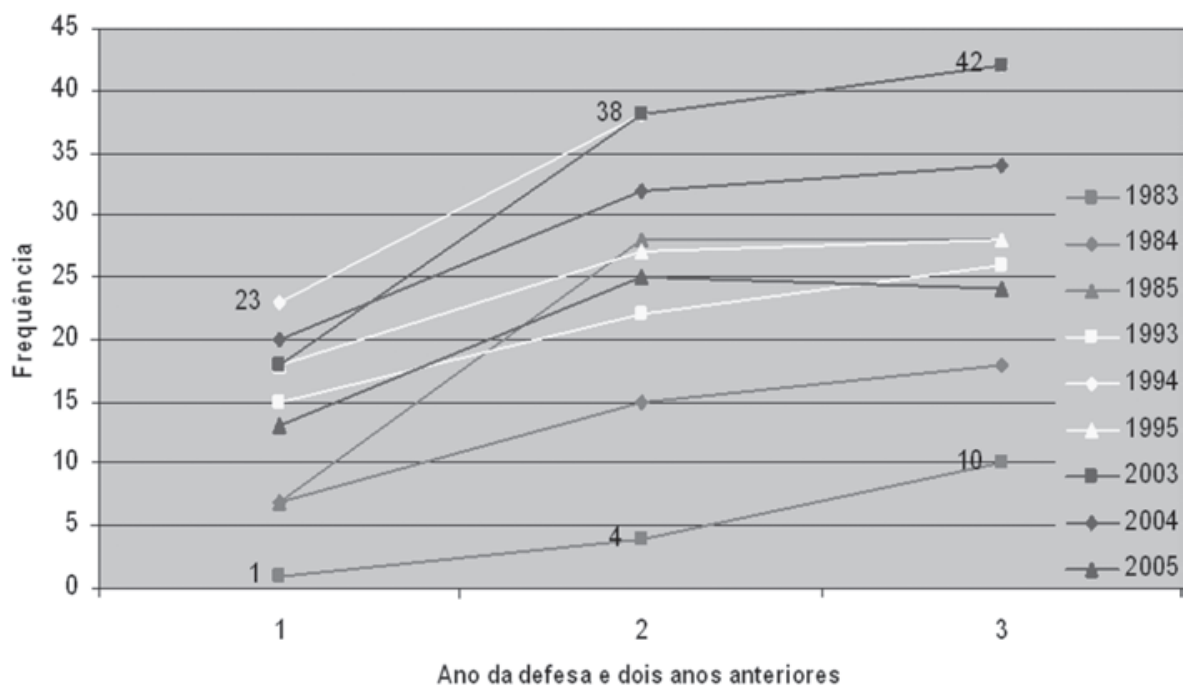


Em vista disso, observa-se significativo aumento no número de títulos citados mais rapidamente entre a década de 1980 e as duas últimas. A explicação para isso pode estar no fato de que, mais uma vez, nos anos pesquisados da década de 1980 (1983-85), não existiam, praticamente, periódicos eletrônicos e muito menos disponíveis na rede. Isso só foi acontecer mais freqüentemente no final da mesma década.

Observa-se ainda, na figura 4, ligeira vantagem da década de 2000 em relação à de 1990 no decorrer dos três anos citados, no que se refere a citar mais rapidamente. Isso fica mais evidente na próxima figura, que apresenta a freqüência relativa dos anos citados nas três décadas.

$\mathrm{Na}$ figura 5 compreende-se que a linha da década de 2000 (azul) segue abaixo das outras duas. Isso pode indicar que as dissertações/teses, dessa década, citam títulos de periódicos mais recentes, enquanto a linha da década de 1980 (verde) segue acima das outras, evidenciando possivelmente um comportamento de citação de títulos mais antigos.

Portanto, é prudente afirmar que as dissertações/teses têm comportamentos diferentes nas três décadas pesquisadas. Ou seja, os títulos de periódicos parecem estar sendo citados mais rapidamente.

\section{CONCLUSÕES}

Tendo em vista a questão principal de saber como a produção do conhecimento científico e pesquisadores,

FIGURA 5

Comportamento dos anos citados por freqüência relativa

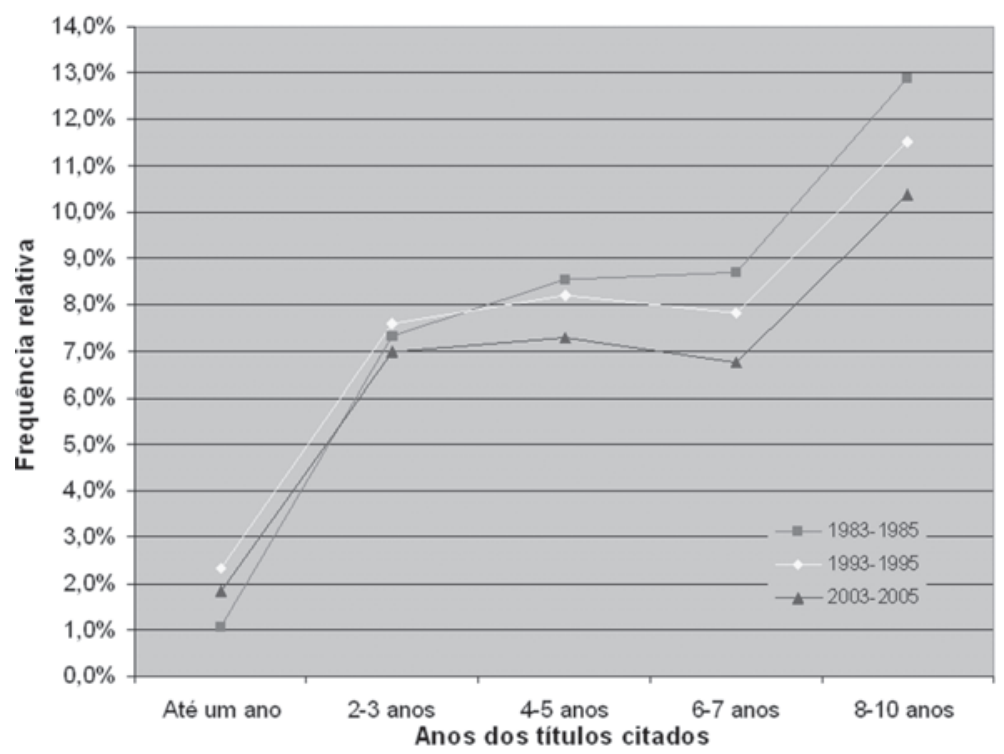

Ci. Inf., Brasília, v. 36, n. 2, p. 7-15, maio/ago. 2007 entendidos aqui como sujeitos cognocente, têm sido afetados pela comunicação eletrônica (alteração de tempo e espaço nos estoques de periódicos), conjecturou-se que a análise dos títulos de periódicos citados e seus respectivos anos nas dissertações/teses de um determinado domínio - desde a introdução dos primeiros periódicos eletrônicos (início da década de 1980), passando pelas redes (por volta década de 1990) até a implementação desses recursos em sistemas de informação ou Portais (década de 2000) - pode fornecer elementos favoráveis à compreensão do fenômeno proposto.

Assim, confirmou-se a hipótese, de forma que a produção do conhecimento científico se mostrou diferente nas três décadas pesquisadas (1980, 1990 e 2000) no que se refere à quantidade de periódicos citados e a velocidade que o são feito.

A alteração do tempo nos estoques, concernente à interoperabilidade e à velocidade no acesso, pode refletir na velocidade que os títulos de periódicos são citados. As dissertações/teses das décadas de 2000 e 1990 citam títulos de periódicos mais recentes em relação aos anos de defesa, do que a década de 1980 . Ou seja, os artigos de periódicos estão sendo citados mais rapidamente.

Em contrapartida, a alteração do espaço nos estoques, concernente à maior oferta de títulos, pode refletir no aumento de títulos citados e de ocorrência. A década de 2000 obteve 964 títulos distintos citados, seguida das décadas de 1990 e 1980 com 816 e 458, respectivamente. Obteve também o maior volume de citação: o total de ocorrências registrado em cada década foi de 7.324 , 5.908 e 3.148 , respectivamente. Ainda, na década de 2000, cada dissertação/tese citou em média 60 vezes, seguida das décadas de 1990 e 1980 com 46 e 37 citações, respectivamente.

Portanto, considerando a citação um pressuposto de que o sujeito ao citar assimilou de fato a informação, pode-se afirmar que a mudança nos estoques tem influenciado na produção do conhecimento científico, pois os pesquisadores estão citando mais títulos de periódicos e mais rapidamente. Ou seja, a modificação estrutural (tempo e espaço) no fluxo de informação científica provocada pela comunicação eletrônica não foi somente 
nos estoques. Parece que o sujeito cognoscente também foi influenciado.

Entretanto, assume-se que alteração de tempo e espaço não pressupõe melhor qualidade na assimilação da informação e produção do conhecimento científico em dissertações/teses. Tema que pode ser objeto de outros estudos de outras pesquisas.

Observou-se também neste estudo que o comportamento de núcleo e dispersão, presente nos modelos bibliométricos, mostrou-se praticamente válido, independentemente do tipo de suporte. Os 20\% dos títulos citados representam 80\% das ocorrências ou citações, apesar de tanto o núcleo quanto a dispersão sofrerem progressivo aumento nas três décadas. Por exemplo, na década de 1980, o núcleo (que abarca $80 \%$ das ocorrências) é formado por 80 títulos de periódicos, seguido dos 107 e 132 títulos nas décadas de 1990 e 2000, respectivamente.

Ademais, é preciso reconhecer que, além da dinamização no acesso, existiram outros avanços durante as décadas pesquisadas apoiados na tecnologia da informação que, certamente, influenciaram na alteração de tempo e espaço da produção do conhecimento científico. Por exemplo, a ampla comercialização de computadores, o aumento na capacidade de processamento de informação, nesses, as bases de dados bibliográficos e a comutação bibliográfica (Comut).

A ressalva a se fazer em um trabalho como este é com relação à normalização das referências bibliográficas das dissertações/teses. Um dos erros mais comuns se refere à falta de padronização nas abreviações dos títulos de periódicos. Outros erros: muitos trabalhos não apresentavam o volume e número dos títulos de periódicos, e a localização da seção da referência não estava sempre no final do trabalho. Acredita-se que essa seja um dos maiores desafios de pesquisas como esta.

Outra dificuldade neste tipo de pesquisa se refere à própria coleta de dados. Embora a disponibilidade na rede das dissertações/teses tenha facilitado a coleta e manipulação dos dados, ocorreram alguns problemas. Muitos trabalhos não permitiam ser copiados e transferidos para o aplicativo Word, pois foram digitalizados em formato imagem. Essa situação se manteve até a década de 1990. Uma solução seria uma outra forma de digitalização que permita a reprodução, facilitando os trabalhos bibliométricos em dissertações/ teses digitais brasileiras.
Notas

[1] Artigo elaborado com base na dissertação de mestrado de Costa (2007), intitulada "Análise do uso de periódicos científicos na transição do meio impresso ao eletrônico em dissertações e teses: o impacto do Portal de Periódicos/Capes na produção do conhecimento", sob orientação do professor doutor Raimundo N. M. dos Santos.

[2] Dados extraídos do Portal: www.periodicos.capes.gov.br. Acesso em: 23 jul. 2007.

[3] BELKIN, Nicholas J. Anomalous States of Knowledge as Basis for Information Retrieval. The Canadian Journal of Information Science, v. 5, p. 133-143, 1980.

[4] A lista dos títulos analisados e suas distribuições bibliométricas em tabelas podem ser consultadas e/ou utilizadas para futuros trabalhos nos anexos da dissertação de Costa (2007).

[5] O acesso não é uma condição suficiente para a citação, mas é necessário (tradução nossa).

Artigo submetido em 04/09/2007 e aceito em 17/04/2008

\section{REFERÊNCIAS}

AMORIM, Antonio M.; VERGUEIRO, Waldomiro. Consórcios de bibliotecas no Brasil: um desafio à democratização do conhecimento. Perspectivas em Ciência da Informação, v. 11, n. 1, p. 32-47, jan./abr. 2006. Disponível em: <www.scielo.br/pdf/pci/v11n1/ v11n1a04.pdf $>$. Acesso em: 23 jul. 2007.

BARRETO, Aldo de A. Mitos e lendas da informação: o texto, o hipertexto e o conhecimento. DataGramaZero, v. 8, n. 1, fev. 2007. Disponível em: <http://www.dgz.org.br/fev07/F_I_art.htm >. Acesso em: 23 jul. 2007.

- Mudança estrutural no fluxo do conhecimento: a comunicação eletrônica. Ciência da Informação, Brasília, v. 27, n. 2, p. 122-127, maio/ago. 1998. Disponível em: <www.scielo.br/pdf/ci/v27n2/ barreto.pdf $>$. Acesso em: 23 jul. 2007.

BIOJONE, Mariana R. Os periódicos científicos na comunicação da ciência. São Paulo: Educ: Fapesp, 2003. $155 \mathrm{p}$. 
CAPURRO, R. Epistemologia e Ciência da informação. In: ENCONTRO NACIONAL DE PESQUISA EM CIÊNCIA DA INFORMAÇÃO, 5., 2003, Belo Horizonte. Anais eletrônicos... Belo Horizonte: Escola de Ciência da Informação da UFMG, 2003. 1 cd-rom. Disponível em: < http://www.capurro.de/enancib_p.htm. $>$. Acesso em: 23 jul. 2007.

CEDÓN, Beatriz V. A Internet. In: CAMPELLO, Bernadete S.; CEDÓN, Beatriz V.; KREMER, Jannette M. (Org.). Fontes de informação para pesquisadores e profissionais. Belo Horizonte: Editora UFMG, 2003. p. 275-300.

COSTA, Rubenildo O. da. Análise do uso de periódicos científicos na transição do meio impresso ao eletrônico em dissertações e teses: o impacto do Portal de Periódicos/Capes na produção do conhecimento. 2007. 142 f. Dissertação (Mestrado) - Curso de Pós-Graduação em Ciência da Informação, Pontifícia Universidade Católica de Campinas, Campinas, 2007. Disponível em: <http:// www.bibliotecadigital.puc-campinas.edu.br/tde_busca/ arquivo.php? codArquivo=256>. Acesso em: 23 jul. 2007.

HARNAD, Stevan; BRODY, Tim. Comparing the impact of Open Access (OA) vs. non-OA articles in the same journals. D-Lib Magazine, v. 10, n. 6, June 2004. Disponível em: <www.dlib.org/dlib/june04/harnad/ 06harnad.html>. Acesso em: 23 jul. 2007.

KING, Donald W.; TENOPIR, Carol. A publicação de revistas eletrônicas: economia da produção, distribuição e uso. Ciência da Informação, Brasília, v. 27, n. 2, p. 176 182, maio/ago. 1998. Disponível em: <www.scielo.br/ pdf/ci/v27n2/king.pdf >. Acesso em: 23 jul. 2007.

KOBASHI, Nair Y.; SANTOS, Raimundo N. M. dos. Institucionalização da pesquisa científica no Brasil: cartografia temática e de redes sociais por meio de técnicas bibliométricas. TransInformação, v. 18, n. 1, p. 27-36, jan./abr. 2006. Disponível em: <http:// revistas.puc-campinas.edu.br/transinfo/ viewarticle.php?id=144>. Acesso em: 23 jul. 2007.

KRZYZANOWSKI, Rosaly F; TARUHN, Rosane. Biblioteca eletrônica de revistas científicas internacionais: projeto de consórcio. Ciência da Informação, Brasília, v. 27, n. 2, p. 193-197, maio/ago. 1998. Disponível em: <www.scielo.br/pdf/ci/v27n2/ 2729813.pdf>. Acesso em: 23 jul. 2007.
LAWRENCE, Steve. Free online availability substantially increases a paper's impact. Nature: webdebates, 2001a. Disponível em: <http:// www.nature.com/nature/debates/e-access/Articles/ lawrence.html>. Acesso em: 23 jul. 2007.

. Online or invisible?. Nature, v. 411, n. 6837, p. 521, 2001b. Disponível em: < citeseer.ist.psu.edu/ online-nature01>. Acesso em: 23 jul. 2007.

MARCONDES, Carlos H.; GOMES, Sandra L. R. O impacto da internet nas bibliotecas brasileiras. TransInformação, Campinas, v.9, n.2, p. 57-68, maio/ago. 1997.

PARLEMITI, Rosalba; POLITY, Yolla. Dynamiques de linstitucionnlisation sociale et cognitive dês sciences de linformation. In: BOURE, $\mathrm{R}$ (Ed). Les origines dês Sciences de linformation et de la communication: regards croisés. Paris: PUS, 2002. p. 95-123.

PAULA NETO, Sidney de. Compartilhamento de recursos de aprendizagem e pesquisa: estudo de consórcios acadêmicos de periódicos eletrônicos. 2005. 136 f. Dissertação (Mestrado em Ciência da Informação) Centro de Ciências Sociais Aplicadas, Pontifícia Universidade Católica de Campinas, 2005.

PRICE, Derek de Solla. Enfermidades da ciência. In: . A ciência desde a babilônia. São Paulo: USP, 1976. p. 143-171.

ROWLEY, Jennifer. The question of electronic journals. Library Hi Tech, v. 18, n. 1, p. 46-54, 2000.

SHIN, Eun-Ja. Measuring the impact of electronic publishing on citation indicators of education journals. Libri, v. 54, p. 221-227, 2004. Disponível em: $<$ www.librijournal.org/pdf/2004-4pp221-227.pdf $>$. Acesso em: 23 jul. 2007.

STUMPF, Ida R. C. Passado e futuro das revistas científicas. Ciência da Informação, v. 25, n. 3, 1996. Disponível em: <www.ibict.br/cionline/include/ getdoc.php? $\mathrm{id}=846 \&$ article $=504 \&$ mode $=p d f>$. Acesso em: 23 jul. 2007.

TEST A, James; MCVeigh, Marie E., The impact of open access journals: a citation study by Thomson ISI. 2004. Disponível em: <http://scientific.thomson.com/ts/ media/presentrep/acropdf/impact-oa-journals.pdf $>$. Acesso em: 23 jul. 2007. 